520

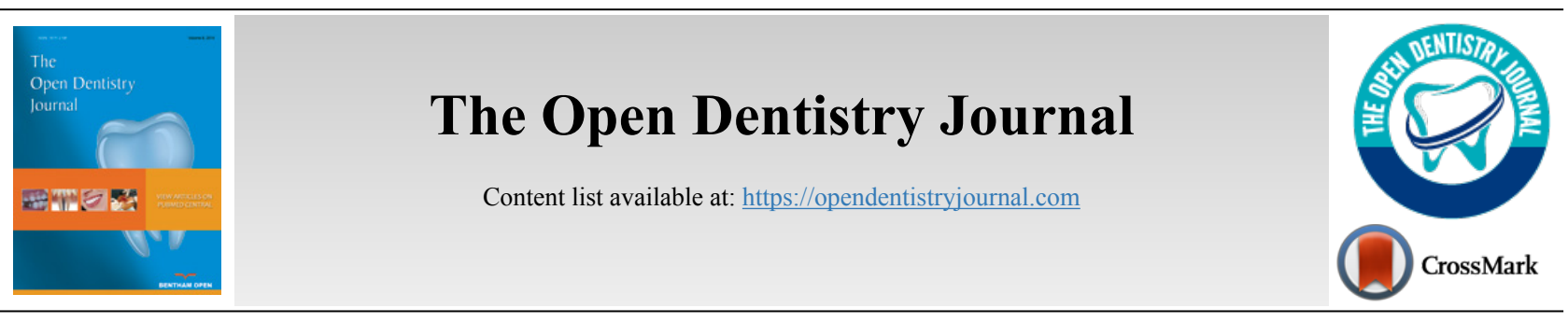

RESEARCH ARTICLE

\title{
Perceived Practitioner Barriers to the Management of Orofacial Pain in the Kingdom of Saudi Arabia: A Cross-sectional Study
}

\author{
Emad M. Hadlaq ${ }^{1, *}$
}

${ }^{\prime}$ Department of Oral Medicine and Diagnostic Sciences, College of Dentistry, King Saud University, Riyadh, Saudi Arabia

\begin{abstract}
:
Background:

Orofacial Pain (OFP) is a group of non-dental painful conditions affecting the oral cavity and facial area.

Objectives:

The objective of this study was to explore which barriers to manage the patient with chronic OFP as perceived by general dentists versus dental specialists and to investigate whether if professionals with degrees from their home country versus another country or number of years of professional experience differ in their perceptions.
\end{abstract}

\section{Methods:}

A closed-end questionnaire was hand-delivered to 600 participants [300 general dentists and 300 dental specialists] in four major provinces in Saudi Arabia. Demographic data were expressed as frequency. Proportional $t$-tests and chi-square tests were used to analyse intergroup differences Statistical significance for all analyses was set at P-value $<0.05$.

Results:

Overall, the response rate was $56.6 \%(340 / 600)$. Around two-thirds of the participants were general dentists $(60.9 \%)$, while the remainder were dental specialists (39.1\%). There was an obvious consensus by the participants that "Low payment/reimbursement" and "Lack of OFP knowledge" were among the most common barriers ( $85 \%$ and $83.5 \%$, respectively). In contrast, "Legal risks" were the least frequently reported factor (38.8\%). The most commonly reported barrier by general dentists was "Shortage of patients/lack of demand;" this was significantly different from the experience of dental specialists $(87 \%$ vs. $72.2 \%$; P-value $<0.01)$. In terms of the country of graduation or years of experience, there were no significant differences.

\section{Conclusion:}

The study demonstrates the existence of many significant barriers other than OFP knowledge, such as reimbursement, facility and demand that could present obstacles and challenges to the management of OFP by general dentists and dental specialists. Most participants believed that dentists should manage this condition and that OFP courses should be included in the dental school curriculum.

Keywords: Barriers, Clinical research study, Dentist, Orofacial pain, Recommendations, Survey.

\begin{tabular}{l|l} 
Revised: August 7, 2020 & Accepted: August 17, 2020 \\
\hline
\end{tabular}

\section{BACKGROUND}

The role of dental practitioner has expanded from treating pain arising from only dental structures "odontogenic pain" to the management of pain in orofacial area arising from regions of the face and mouth that are not related to dental structures "nonodontogenic pain" [1, 2]. Orofacial Pain (OFP) is a group

* Address correspondence to this author at the Department of Oral Medicine and Diagnostic Sciences, College of Dentistry, King Saud University, P.O Box 60169 Riyadh, 11545 Saudi Arabia; Tel: +966540984774; E-mail: ehadlaq@ksu.edu.sa of painful conditions affecting the oral cavity and facial area, which can be somatic, neuropathic or psychological. It includes Temporomandibular Joint Disorders (TMDs), masticatory musculoskeletal pain, cervical musculoskeletal pain, neurovascular pain, neuropathic pain, sleep disorders related to orofacial pain, orofacial dystonias, headaches, intraoral, intracranial, extracranial, and systemic disorders that cause OFP, as outlined by the American Academy of Orofacial Pain [3].

OFP can have a significantly negative impact on the 
quality of life directly \& indirectly, as it causes functional limitation in chewing and speaking, and social and physical disability. Moreover, OFP is also associated with psychological discomfort and disability [4], and has a severe impact on daily, social, and work activities [5]. Recognition of these disorders is an essential skill for dental care providers since patients mainly seek dental care due to pain.

Questionnaire Surveys of dentists is one of the commonly used research methods to provide information on their knowledge and attitudes. There are several limitations and potential errors that need to be considered when conducting a survey: coverage error, sampling error, non-response error and measurement error [6]. The response rate of a survey is considered as an indicator of survey quality. It is not the only measure of quality. Non-response bias has grown in importance as a measure of survey quality; non-response and nonresponse bias are different. Response bias or nonresponse bias occurs when those who respond differently from those who have no interest in the outcome of the survey. Another significant potential error is measurement error, it occurs when inappropriate wording, design or mode of the questionnaire leads to an inaccurate answer. To reduce coverage error, every member of the survey population should have the same chance as any other of being selected into the survey sample to receive a questionnaire. Sampling errors can be reduced when the sample size is increased to ensure that the sample adequately represents the entire population. The trade-off is that the larger the population, the more difficult it is to correctly identify every member and their contact details. Resources for research are always limited. Therefore, there is a balance between the size of the sample and the costs of contacting the sample members effectively [7].

Several surveys have assessed the OFP knowledge levels among dentists, assuming that this is the only barrier to OFP practice and found different knowledge levels between General Dental Practitioners (GDPs) and dental specialists [7 - 12]. However, several other dentist and patient-related barriers may also exist, but no previous report has addressed this. Therefore, there is a need for a comprehensive understanding of the barriers to providing OFP care.

The objective of this study was to explore which barriers to manage patients with chronic OFP as perceived by general dentists versus dental specialists and to investigate whether if professionals with degrees from their home country versus another country or number of years of professional experience differ in their perceptions.

\section{MATERIALS AND METHODS}

A human research ethical approval was consulted and obtained through King Saud University, Faculty of Dentistry (KSU-FD), Riyadh, Saudi Arabia (\#IR0164). A cross-sectional survey was performed using a two-part English language questionnaire that included 14 close-ended questions (appendix 1). The first section focused on socio-demographic and descriptive parameters, including age, sex, specialty, experience, type of practice, and country of graduation. The second section assessed potential barriers to the management of patients with OFP and relevant recommendations. There was a cover letter attached to the questionnaire, including information regarding the background and objective of the study. The survey was conducted from February to August 2018.

No prototype questionnaire that specifically assesses barriers to the management of chronic orofacial pain was available. Therefore, five local experts in orofacial pain and dental professionals were asked to list 5 issues that may encounter OFP practitioners to provide the service, which were used to construct the closed-ended questionnaire. Then the questionnaire was pilot tested by 10 dental practitioners to assess its feasibility and to determine the time needed to conduct the survey. Their comments were thoroughly considered in the final modification of the survey. The study was hand-delivered to 600 participants (300 GDPs and 300 dental specialists) in the four major provinces in Saudi Arabia: Riyadh, Makkah, Asir, and Eastern Province. Participants were selected randomly as representative of the Saudi dental community and included governmental hospitals, large private dental practices (> 10 dentists), and dental schools. Inclusion criteria were registered with the Saudi Commission for Health Specialties and a minimum of 2 years' experience. Prior to data collection, written informed consent was obtained. There was no financial incentive for participants to complete the questionnaire. The study was performed with anonymized data.

Based on the pilot study, the minimum sample size was 330 participants (assuming the alpha level of 0.05 and a statistical power of $85 \%$ with an estimated proportional = 0.65). Statistical analysis was performed using SPSS software (IMP SPSS statistics, Version 22, Armonk, NY, 2013). Age, sex, specialty, years of experience, type of practice, and country of graduation responses were expressed as frequency. Proportional $t$-tests and chi-square tests were used to analyse intergroup differences. Statistical significance for all analyses was set at $\mathrm{P}$-value $<0.05$.

\section{RESULTS}

\subsection{Participants' Demographics}

Overall, the response rate was $56.6 \%(340 / 600)$. Around two-thirds of the participants were GDPs $(60.9 \%)$, while the remainder were dental specialists (39.1\%). The response rate of GDPs was $69 \%(207 / 300)$, while of the specialists was $44.3 \%$ (133/300). The questionnaires were completed by 168 males (49.4\%) and 172 females (50.6\%). Seventy-four percent had a Saudi educational background (253/340), and around 52\% of participants were $<30$ years old. Overall, 71.1\% (247/340) had $<10$ years' occupational experience. Participants were either employed in the governmental sector $(37.3 \%)$, at academic institutes $(28.2 \%)$, in private practice $(20.8 \%)$, or in a combination of these. Participants' demographics are shown in Table 1. 
Table 1. Demographic characteristics of study participants are presented in numbers and percentages.

\begin{tabular}{|c|c|c|}
\hline \multirow{2}{*}{ Sex } & Female & $172(50.6 \%)$ \\
\hline & Male & $168(49.4 \%)$ \\
\hline \multirow{3}{*}{ Age } & $<30$ years old & $177(52 \%)$ \\
\hline & $30-40$ years old & $105(30.9 \%)$ \\
\hline & $>40$ years old & $58(17.1 \%)$ \\
\hline \multirow{2}{*}{ Graduation Country } & Saudi Arabia & $253(74.4 \%)$ \\
\hline & Other countries & $87(25.6 \%)$ \\
\hline \multirow{9}{*}{ Specialty } & General practitioner & $207(60.9 \%)$ \\
\hline & Endodontics & $23(6.8 \%)$ \\
\hline & Periodontics & $15(4.4 \%)$ \\
\hline & Orthodontics & $15(4.4 \%)$ \\
\hline & Pedodontics & $17(5 \%)$ \\
\hline & Prosthodontics & $28(8.2 \%)$ \\
\hline & Restorative & $12(3.5 \%)$ \\
\hline & Oral Surgery & $13(3.8 \%)$ \\
\hline & Oral Medicine & $10(2.9 \%)$ \\
\hline \multirow{3}{*}{ Experience } & $<10$ Years & $247(72.6 \%)$ \\
\hline & 10-20 Years & $57(16.8 \%)$ \\
\hline & $>20$ Years & $36(10.6)$ \\
\hline \multirow{4}{*}{ Dental practice setting } & Government & $127(37.4 \%)$ \\
\hline & Academic & $96(28.2 \%)$ \\
\hline & Private & $71(20.9 \%)$ \\
\hline & Combined & $46(13.5 \%)$ \\
\hline
\end{tabular}

\subsection{Perceived Barriers}

Participants perceived "Low payment/reimbursement" and "Lack of orofacial pain knowledge" as the most common barriers to practicing OFP care ( $85 \%$ and $83.5 \%$, respectively). In contrast, "Legal risks" were the least reported issue (38.8). Almost equal proportions of participants considered OFP practice as being $(49.4 \%)$ or not being (43.5\%) "Time consuming". Detailed responses are listed in Table 2.

Table 2. Participants' responses to potential perceived barriers: This table shows the responses to each potential barrier in percentage and number. Proportional $t$-tests were used to compare the responses.

\begin{tabular}{|c|c|c|c|}
\hline Variable & Agree & Not sure & Disagree \\
\hline Lack of orofacial pain knowledge & 284 & 35 & 21 \\
& $83.5 \%$ & $10.3 \%$ & $6.2 \%$ \\
\hline Shortage of patients/lack of demand & 276 & 12 & 52 \\
& $81.2 \%$ & $3.5 \%$ & $15.3 \%$ \\
\hline Time consuming & 168 & 24 & 148 \\
& $49.4 \%$ & $7.1 \%$ & $43.5 \%$ \\
\hline Low payment /reimbursement & 289 & 29 & 22 \\
& $85 \%$ & $8.5 \%$ & $6.5 \%$ \\
\hline Legal risks & 132 & 38 & 170 \\
& $38.8 \%$ & $11.2 \%$ & $50 \%$ \\
\hline Lack of facility & 270 & 19 & 51 \\
& $79.4 \%$ & $5.6 \%$ & $15 \%$ \\
\hline
\end{tabular}

*The third barrier, "Time consuming," was the only insignificant (P-value $=0.1)$.

The barrier most frequently reported by GDPs was "Shortage of patients/lack of demand;" this was significantly different from the barriers experienced by dental specialists ( $87 \%$ vs. $72.2 \%$; P-value $<0.01$ ). On the other hand, the greatest barriers experienced by dental specialists were "Lack of orofacial pain knowledge" (86.5\%) and "Low payment /reimbursement" (86.5\%). However, no other differences were significant between GDPs and specialists. Both groups noted "Legal risks" (41.5\% and $34.6 \%$, respectively) as the least important barrier (Fig. 1).

Graduates from Saudi programs mostly reported "Shortage of patients/lack of demand" (87\%) as a barrier, whereas the statement "Low payment/reimbursement" was most common among graduates from non-Saudi programs. Both graduate groups reported "Legal risks" ( $44.8 \%$ and $36.8 \%$ respectively) as the least common barrier. Differences between the two graduate groups were not statistically significant (Fig. 2).

GDPs and dental specialists reported the same barrier factors, regardless of years of experience. Although the differences were not significant, "Shortage of patients/lack of demand" and "Lack of facility" were directly proportional to years of experience. On the other hand, the "Time consuming" response was in Inverse proportion to years of experience (Fig. 3). There were no other significant differences within each group related to sex, country of graduation, or year of experience.

Table 3. Participants' responses to recommendations: This table shows responses of each recommendation in percentage and number. Proportional $t$-tests showed that all recommendations.

\begin{tabular}{|c|c|c|c|}
\hline Variable & Agree & Not sure & Disagree \\
\hline $\begin{array}{c}\text { You believe dentists should manage a } \\
\text { patient with orofacial pain }\end{array}$ & 254 & 45 & 41 \\
$74.7 \%$ & $13.2 \%$ & $12.1 \%$ \\
\hline $\begin{array}{c}\text { You believe a course of orofacial pain } \\
\text { should be included in the dental education } \\
\text { curriculum }\end{array}$ & 326 & 1 & 13 \\
suggested were highly significant (P-value $<0.01)$. & $0.3 \%$ & $3.8 \%$ \\
\hline
\end{tabular}




\subsection{Perceived Recommendations}

Agreements to the two proposed recommendations were highly significant (P-value $<0.01)$. Overall, $74.7 \%$ of participants agreed that dentists should manage patients with
OFP, while $25.3 \%$ were not sure about or disagreed with this concept. Most GDPs and dental specialists $(95.9 \%)$ in the study recommended adding a course on OFP care to dental education curricula (Table 3).

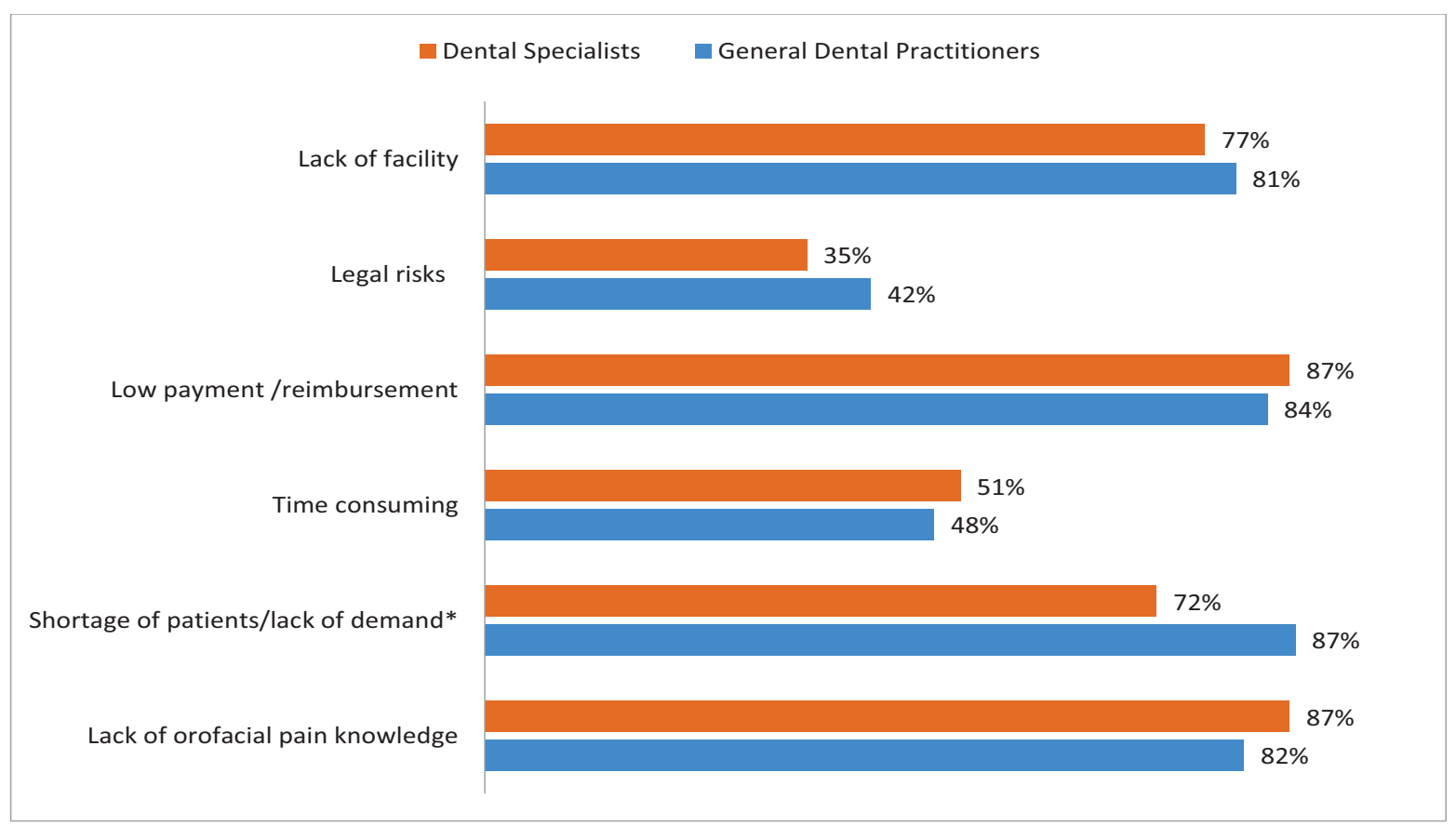

Fig. (1). Respondents were divided into general dental practitioners and specialists. This graph shows the percentage of each group who agreed that each point was a barrier to offering orofacial pain care. The proportional $t$-test was used to compare between the two groups. *The second barrier "Shortage of patients/lack of demand" was a significantly higher perceived barrier among general dental practitioners than among dental specialists (P-value $<0.01)$

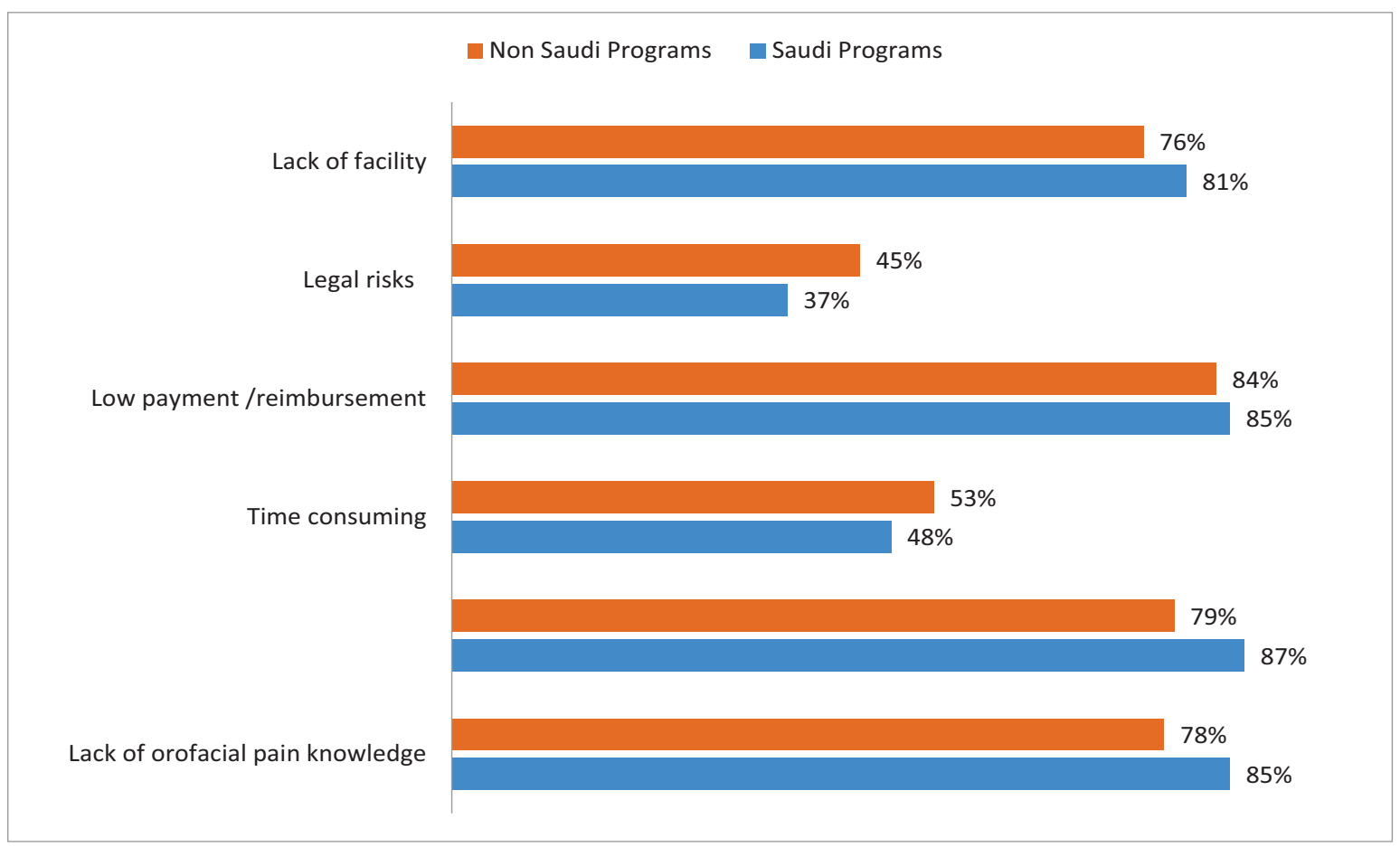

Fig. (2). Respondents were divided into two groups, according to the country of graduation. This graph shows the percentage of each group who agreed that each point was a barrier to offering orofacial pain care. A proportional $t$-test was used to compare between the two groups. There was no significant difference between graduates of Saudi programs and non-Saudi programs. 


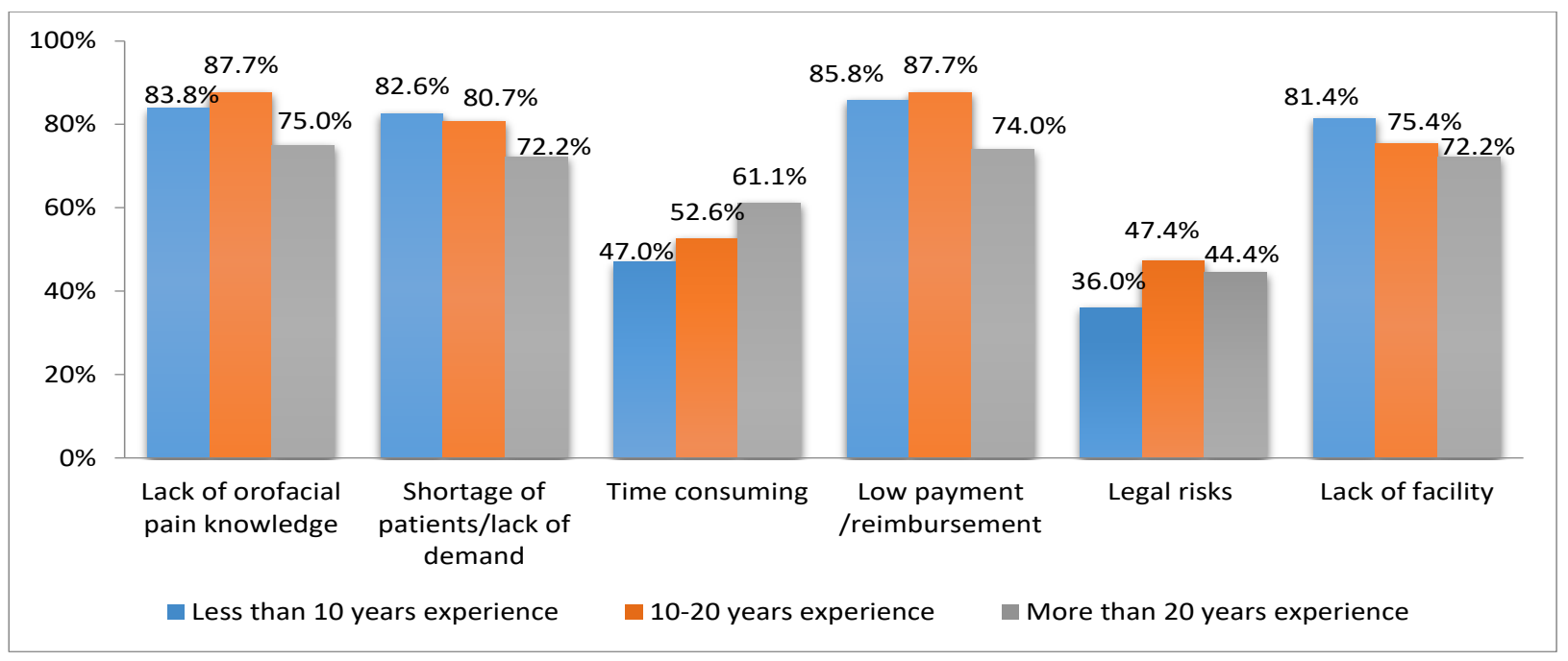

Fig. (3). Respondents were divided into three groups according to years of occupational experience. This graph shows the percentage of each group who agreed that each point was a barrier to offering orofacial pain care. The chi-square test was used to compare the three groups. There was no significant difference among the groups.

\section{DISCUSSION}

Pain in dentistry is usually related to oral diseases [13] or clinical procedures, such as restoration [14], implant insertion [15], miniscrew placement [16], tooth avulsion [17], combined surgical-orthodontic therapy [18], temporomandibular therapy [19]. Therefore any patient presenting with a chief complaint of toothache should be first evaluated for an odontogenic cause of pain. Odontogenic toothache occurs when there is noxious stimulation affecting the hard or soft tissue of the oral cavity. It can be identified by clinical evidence of abnormality (e.g. fracture, caries, ulcers), ability to be reproduced during the examination and can be eliminated by local anesthesia. Usually, the odontogenic toothache is localized and the quality of pain is dull, aching, or throbbing. It is also characterized by sensitivity to temperature, percussion and digital pressure [20]. However, intraoral pain may be derived from other tissues of the head and neck, which is nonodontogenic in origin. The nonodontogenic toothache is a heterotopic pain that occurs in the absence of any clinically evident cause in the oral cavity. It is a condition with multiple pathophysiological causes and may arise from musculoskeletal, neuropathic, vascular, neurovascular tissue in addition to extra-cranial, intracranial structures and systemic disorders that may cause OFP [21]. The primary distinguishing features of this kind of pain are location, severity, quality, and pattern of occurrence. For example, the neurovascular toothache is characterized by periods of total remission between episodes and generally presented as moderate to severe diffuse throbbing, pulsing, or pounding pain lasts hours to days. Neuropathic toothache, trigeminal neuralgia, is episodically described as a severe sharp, shooting, or burning pain that lasts a few seconds and is restricted to the peripheral distribution of the affected nerve branch. Muscular toothache is usually constant as deep dull aching diffuse pain with a moderate intensity that increases on function [22]. Other clinical characteristics of non-odontogenic toothache, which help to differentiate it from an odontogenic toothache are [23]:
1- Local provocation of the site of pain does not increase the pain, whereas local provocation at the source of pain increases the pain not only at the source but also increases the pain at the site.

2- Local anesthetic injection of the site of pain does not relieve the pain, while blocking the source by local anaesthesia decreases the pain at the source, as well as the site.

OFP is challenging to diagnose and manage, given the complexity of the pain mechanism and inadequate education on OFP. In this study, most participants (74.4\%) believed that the management of OFP conditions forms part of dental professional responsibility, highlighting the importance of addressing this field and its barriers. Most participants (83.5\%) reported a lack of OFP knowledge as a major barrier, and 95.9\% recommended that OFP should gain more attention in dental curricula. This finding agreed with previous reports. For example, Klasser and Gremillion reported on OFP education in the US since 1973 [24] and found that although OFP education had improved, it still lacked in some respects. Ziegeler et al. found that $83 \%$ of German senior dental students reported that OFP was only included in a lecture on another topic [25]. Thirty percent of senior German dental students did not feel confident at all in diagnosing OFP, while $48 \%$ were somewhat confident. Klasser and Greene recommended OFP study in predoctoral dental education [26]. The International Association for the Study of Pain (IASP) has recently suggested an interprofessional pain curriculum outline, which included multiple topics on OFP [27]. Although the present study confirmed that lack of knowledge of OFP was a major factor, we found no differences between graduates of Saudi and nonSaudi programs. However, Al Khotani et al. found dental professional knowledge in Saudi Arabia was significantly less than that of their Swedish counterparts [10], suggesting gaps in the Saudi dental educational system.

OFP practice is undoubtedly time-consuming in both diagnosis and management; however, this was the only 
potential barrier showing conflict among our participant groups, with almost equal proportions agreeing (49.4\%) and disagreeing $(43.5 \%)$ that this is a barrier. This may be because OFP could be overlooked as a health problem that requires prioritising by the physician. In addition, years of experience might also have contributed to this conflict. We noted that participants with more years of experience tended to agree more that this was an issue. It is possible that practitioners with more years of experience have encountered more OFP patients, so that they are more aware of how time-consuming OFP practice could be. We also found that $85 \%$ of our study sample considered that "low payment /reimbursement" is a significant barrier; this may because OFP care is time-consuming and does not have as high a cost-effort ratio as other dental procedures.

Most of our participants underestimated OFP prevalence: $81.2 \%$ of participants reported that shortage of patients/lack of demand was one of the major barriers, although the specialists agreed less with this statement than did GDPs. This perception was inconsistent with the reported prevalence of various OFP conditions, which affects approximately $10 \%-26 \%$ of the adult population and up to $50 \%$ of the elderly $[28,29]$. For example, the National Institute of Dental and Craniofacial Research reported that the prevalence of Temporomandibular Joint Disorder (TMJD) was 5\%-12\% [30]. A systematic review article showed that masticatory myofascial pain disorders, as one of the TMD subgroups, occurred in about $45.3 \%$ of TMD patients [31]. Neuropathic OFP is much more heterogeneous and its true prevalence is unknown. The incidence of trigeminal neuralgia varies from 4.3 to 27 cases per 100,000 per year [32, 33 ] with a $0.3 \%$ prevalence [33], whereas glossopharyngeal neuralgia has an incidence of $0.2-0.7$ cases per 100,000 persons per year [34, 35]. Additionally, the reported prevalence of continuous neuropathic OFP conditions, such as persistent idiopathic facial pain (formerly known as atypical odontalgia, atypical facial pain, or phantom tooth pain) was $0.03 \%-1 \%$ in the general population $[33,36]$ and $2.1 \%-10.6 \%$ in a tertiary OFP centre [36]. Generally, the prevalence of burning mouth is between 0.7 to $5 \%$ of the population $[37,38]$. In Saudi Arabia, the reported prevalence of TMJDs is $21 \%-34 \%$, with no available data for other OFP disorders [39].

Another consensus response involved the lack of facility, in accordance with the current best evidence. Based on the patient's chief complaint and individual needs, the diagnosis of OFP conditions may need advanced diagnostic tests, advanced imaging modalities, access to controlled medications, and a multidisciplinary team approach. The accessibility of facilities may require an OFP practice in a hospital setting or tertiary pain centre. This may explain the high agreement on this factor, as most participants were GDPs and most likely work in primary dental clinics, whereas dental specialists agreed less with this statement.

\section{LIMITATIONS}

The present study had several limitations. Participants were limited to dentists; however, OFP patients may express other opinions about barriers to good care. Hence future studies should investigate patients' perceptions during the process of seeking oral care. Additionally, the percentage of senior dentists was low in this study. The years of experience was a key factor that may independently influence the barriers perceived, since senior dentists will have encountered more patients with OFP. However, the distribution by age and years of experience was consistent with the distribution of dentists in the country and the potential subjects were selected randomly in this study. Moreover, there have been few previous studies on this topic, so that the newly constructed questionnaire could not be validated; this needs to be addressed in the future. In addition, study participants were limited to four main provinces in Saudi Arabia. Although Riyadh, Makkah, Asir, and Eastern Province are the largest and most diverse in this country, it will be valuable to survey other provinces and investigate if differences across regions exist, to provide a more inclusive database of dentists for future improvements of national health care. Finally, the recruited participants were not randomly selected from different dental sectors within each province. However, the study sample was equally distributed over academic institutes, governmental sectors, and private practices, to compensate in part for bias.

\section{CONCLUSION}

OFP practice is a complex field that is further complicated by multiple barriers. Although OFP education is critical, the current study emphasises that knowledge levels among dentists were not the only barrier that requires addressing; other factors, such as reimbursement, facility, and demand, were also considered barriers. There is a misconception about the prevalence of OFP among dental professionals. OFP courses should be included in dental school curricula to train future dentists. Well-designed educational programs should be planned to target dental specialists and GDPs in Saudi Arabia to ensure the delivery of appropriate patient care at the highest international standards. In addition, there is a critical need to address issues, such as available facilities, to encourage OFP care practice.

\section{ETHICS APPROVAL AND CONSENT TO PARTICIPATE}

The study was approved by the ethical commitee of King Saud University - Faculty of Dentistry (KSU-FD), Riyadh, Saudi Arabia (\#IR0164).

\section{HUMAN AND ANIMAL RIGHTS}

Not applicable.

\section{CONSENT FOR PUBLICATION}

Informed consent was obtained from the participants prior to being enrolled in the study.

\section{AVAILABILITY OF DATA AND MATERIALS}

The data supporting the findings of the article is available from the corresponding author [E.H] upon request.

\section{FUNDING}

None.

\section{CONFLICT OF INTEREST}

The author declares no conflict of interest, financial or otherwise.

\section{ACKNOWLEDGEMENTS}

The author thanks all study participants. The author is grateful to Dr. Maha Al Hamdan, Dr. Shouq Jurays, and Dr. Hassan Khan for assistance with data collection, and to $\mathrm{Mr}$. Nassr Al-Maflehi for statistical analyses. 


\section{APPENDIX 1}

Items and questions used in the survey.

Part I: Demographic Data and Practice Background

Gender

$\square$ Male

$\square$ Female

Age
$\square<30$ years old
$\square \quad 30-40$ years old
$\square>40$ years old

Specialty
$\square$ Endodontist
$\square$ Periodontist
$\square$ Orthodontist
$\square$ Pedodontist
$\square$ Prosthodontist
$\square$ Restorative
$\square$ Oral surgery
$\square$ Oral Medicine
$\square$ General practitioner

Country of Residency, Postgraduate (for specialist) or Bachelor degree (for GP)
- Saudi Arabia
$\square \quad$ Other

Years of experience
$\square \quad<10$ years
$\square$ 11-20
$\square>20$

You are practicing at (can be more than one)
$\square$ Academic institute
$\square$ Governmental sector
$\square$ Private sector

Part II: Thinking about barriers to manage patient with chronic OFP, please indicate the extent to which you agree with the following variables

\begin{tabular}{|l|l|l|l|}
\hline Variable & Agree & Not sure & Disagree \\
\hline Lack of orofacial pain knowledge & & & \\
\hline Shortage of patients/lack of demand & & & \\
\hline Time consuming & & & \\
\hline Low payment /reimbursement & & & \\
\hline Legal risks & & & \\
\hline Lack of facility & & & \\
\hline
\end{tabular}

Part III: In this part of the survey we would like to ask you questions regarding OFP practice

\begin{tabular}{|l|l|l|l|}
\hline & Agree & Not sure & Disagree \\
\hline You believe dentists should manage patient with orofacial pain & & & \\
\hline $\begin{array}{l}\text { You believe a course of orofacial pain should be included in dental education } \\
\text { curriculum }\end{array}$ & & & \\
\hline
\end{tabular}




\section{REFERENCES}

[1] De Laat A. Differential diagnosis of toothache to prevent erroneous and unnecessary dental treatment. J Oral Rehabil 2020; 47(6): 775-81. [http://dx.doi.org/10.1111/joor.12946] [PMID: 32061108]

[2] Koh SWC, Li CF, Loh JSP, Wong ML, Loh VWK. Managing tooth pain in general practice. Singapore Med J 2019; 60(5): 224-8. [http://dx.doi.org/10.11622/smedj.2019044] [PMID: 31187144]

[3] American Academy of Orofacial Pain. Orofacial Pain Available from: https://aaop.clubexpress.com/content.aspx?page_id=22\&club_id $=5084$ 39\&module_id $=107325$

[4] Manjunath G, Prasad K. Prevalence of Orofacial pain among urban adult population of Hubli - Dharwad and its impact on daily living. J Indian Assoc Public Health Dent 2012; 10(19): 7-18.

[5] Oberoi SS, Hiremath SS, Yashoda R, Marya C, Rekhi A. Prevalence of Various Orofacial Pain Symptoms and Their Overall Impact on Quality of Life in a Tertiary Care Hospital in India. J Maxillofac Oral Surg 2014; 13(4): 533-8.

[http://dx.doi.org/10.1007/s12663-013-0576-6] [PMID: 26225024]

[6] Shelley AM, Brunton P, Horner K. Questionnaire surveys of dentists on radiology. Dentomaxillofac Radiol 2012; 41(4): 267-75. [http://dx.doi.org/10.1259/dmfr/58627082] [PMID: 22517994]

[7] Aggarwal VR, Joughin A, Zakrzewska JM, Crawford FJ, Tickle M. Dentists' and specialists' knowledge of chronic orofacial pain: results from a continuing professional development survey. Prim Dent Care 2011; 18(1): 41-4. [http://dx.doi.org/10.1308/135576111794065838] [PMID: 21214979]

[8] Rezaei F, Sharifi R, Shahrezaee HR, Mozaffari HR. Knowledge About Chronic Orofacial Pain Among General Dentists of Kermanshah, Iran. Open Dent J 2017; 11: 221-9.

[http://dx.doi.org/10.2174/1874210601711010221] [PMID: 28553411]

[9] Al-Khotani A, Björnsson O, Naimi-Akbar A, Christidis N, Alstergren P. Study on self-assessment regarding knowledge of temporomandibular disorders in children/adolescents by Swedish and Saudi Arabian dentists. Acta Odontol Scand 2015; 73(7): 522-9. [http://dx.doi.org/10.3109/00016357.2014.997794] [PMID: 25597273]

[10] Al-Khotani A, Naimi-Akbar A, Björnsson O, Christidis N, Alstergren P. Professional knowledge among Swedish and Saudi healthcare practitioners regarding oro-facial pain in children and adolescents. J Oral Rehabil 2016; 43(1): 1-9.

[http://dx.doi.org/10.1111/joor.12330] [PMID: 26134067]

[11] Borromeo GL, Trinca J. Understanding of basic concepts of orofacial pain among dental students and a cohort of general dentists. Pain Med 2012; 13(5): 631-9.

[http://dx.doi.org/10.1111/j.1526-4637.2012.01360.x] [PMID: 22494500]

[12] Gnauck M, Magnusson T, Ekberg E. Knowledge and competence in temporomandibular disorders among Swedish general dental practitioners and dental hygienists. Acta Odontol Scand 2017; 75(6): 429-36.

[http://dx.doi.org/10.1080/00016357.2017.1331373] [PMID: 28554268]

[13] Sharma R, Pallagatti S, Aggarwal A, Sheikh S, Singh R, Gupta D. A Randomized, Double-Blind, Placebo-Controlled Trial on Clinical Efficacy of Topical Agents in Reducing Pain and Frequency of Recurrent Aphthous Ulcers. Open Dent J 2018; 12: 700-13.

[http://dx.doi.org/10.2174/1745017901814010700] [PMID: 30369980]

[14] Ndagire B, Mwesigwa CL, Ntuulo JM, Mayanja-Kizza H, Nakanjako D, Rwenyonyi CM. Dental Caries Pattern and Treatment Needs among Ugandan Adolescent Students: A Cross-Sectional Study. Int J Dent 2020; 20208135865

[http://dx.doi.org/10.1155/2020/8135865] [PMID: 32256595]

[15] Tallarico M, Ceruso FM, Muzzi L, et al. Effect of Simultaneous Immediate Implant Placement and Guided Bone Reconstruction with Ultra-Fine Titanium Mesh Membranes on Radiographic and Clinical Parameters after 18 Months of Loading. Materials (Basel) 2019; 12(10)E1710

[http://dx.doi.org/10.3390/ma12101710] [PMID: 31130717]

[16] Sfondrini MF, Gandini P, Alcozer R, Vallittu PK, Scribante A. Failure load and stress analysis of orthodontic miniscrews with different transmucosal collar diameter. J Mech Behav Biomed Mater 2018; 87: $132-7$.

[http://dx.doi.org/10.1016/j.jmbbm.2018.07.032] [PMID: 30059839]

[17] Cosme-Silva L, Fernandes LA, Rosselli ER, Poi WR, Martins NDS, de Lima DC. Tooth injuries: Knowledge of parents of public school students from the city of Alfenas, Minas Gerais, Brazil. Dent Traumatol 2018; 34(2): 93-9. [http://dx.doi.org/10.1111/edt.12381] [PMID: 29282852]

[18] Scribante A, Sfondrini MF, Gatti S, Gandini P. Disinclusion of unerupted teeth by mean of self-ligating brackets: effect of blood contamination on shear bond strength. Med Oral Patol Oral Cir Bucal 2013; 18(1): e162-7.

[http://dx.doi.org/10.4317/medoral.18246] [PMID: 23229253]

[19] Kumar R, Pallagatti S, Sheikh S, Mittal A, Gupta D, Gupta S. Correlation Between Clinical Findings of Temporomandibular Disorders and MRI Characteristics of Disc Displacement. Open Dent J 2015; 9: 273-81.

[http://dx.doi.org/10.2174/1874210601509010273] [PMID: 26464595]

[20] Napeñas JJ. Intraoral pain disorders. Dent Clin North Am 2013; 57(3): 429-47.

[http://dx.doi.org/10.1016/j.cden.2013.04.004] [PMID: 23809302]

[21] Yatani H, Komiyama O, Matsuka Y, et al. Systematic review and recommendations for nonodontogenic toothache. J Oral Rehabil 2014; 41(11): $843-52$

[http://dx.doi.org/10.1111/joor.12208] [PMID: 25040436]

[22] Ananthan S, Benoliel R. Chronic orofacial pain. J Neural Transm (Vienna) 2020; 127(4): 575-88

[http://dx.doi.org/10.1007/s00702-020-02157-3] [PMID: 32130516]

[23] Okeson JP. Non-odontogenic toothache. Northwest Dent 2000; 79(5): 37-44.

[PMID: 11413614]

[24] Klasser GD, Gremillion HA. Past, present, and future of predoctoral dental education in orofacial pain and TMDs: A call for interprofessional education. J Dent Educ 2013; 77(4): 395-400. [http://dx.doi.org/10.1002/j.0022-0337.2013.77.4.tb05485.x] [PMID: 23576585]

[25] Ziegeler C, Wasiljeff K, May A. Nondental orofacial pain in dental practices - diagnosis, therapy and self-assessment of German dentists and dental students. Eur J Pain 2019; 23(1): 66-71.

[http://dx.doi.org/10.1002/ejp.1283] [PMID: 29978526]

[26] Klasser GD, Greene CS. Predoctoral teaching of temporomandibular disorders: A survey of U.S. and Canadian dental schools. J Am Dent Assoc 2007; 138(2): 231-7.

[http://dx.doi.org/10.14219/jada.archive.2007.0142]

[PMID: 17272380]

[27] The International Association for the Study of Pain. IASP Terminology Available from: https://www.iasp-pain.org/Education/Content.aspx?ItemNumber=1698

[28] Madland G, Newton-John T, Feinmann C. Chronic idiopathic orofacial pain: I: What is the evidence base? Br Dent J 2001; 191(1): 22-4. [http://dx.doi.org/10.1038/sj.bdj.4801081] [PMID: 11491472]

[29] Macfarlane TV, Blinkhorn AS, Davies RM, Worthington HV. Association between local mechanical factors and orofacial pain: Survey in the community. J Dent 2003; 31(8): 535-42. [http://dx.doi.org/10.1016/S0300-5712(03)00108-8] 14554070]

[30] National Institute of Dental and Craniofacial Research. Prevalence of TMJD and its Signs and Symptoms Available from: https://www.nidcr.nih.gov/research/data-statistics/facial-pain/prevalen ce.

[31] Manfredini D, Guarda-Nardini L, Winocur E, Piccotti F, Ahlberg J, Lobbezoo F. Research diagnostic criteria for temporomandibular disorders: A systematic review of axis I epidemiologic findings. Oral Surg Oral Med Oral Pathol Oral Radiol Endod 2011; 112(4): 453-62. [http://dx.doi.org/10.1016/j.tripleo.2011.04.021] [PMID: 21835653]

[32] Hall GC, Carroll D, Parry D, McQuay HJ. Epidemiology and treatment of neuropathic pain: The UK primary care perspective. Pain 2006; 122(1-2): 156-62.

[http://dx.doi.org/10.1016/j.pain.2006.01.030] [PMID: 16545908]

[33] Mueller D, Obermann M, Yoon MS, et al. Prevalence of trigeminal neuralgia and persistent idiopathic facial pain: A population-based study. Cephalalgia 2011; 31(15): 1542-8.

[http://dx.doi.org/10.1177/0333102411424619] [PMID: 21960648]

[34] Koopman JS, Dieleman JP, Huygen FJ, de Mos M, Martin CG, Sturkenboom MC. Incidence of facial pain in the general population. Pain 2009; 147(1-3): 122-7.

[http://dx.doi.org/10.1016/j.pain.2009.08.023] [PMID: 19783099]

[35] Reddy GD, Viswanathan A. Trigeminal and glossopharyngeal neuralgia. Neurol Clin 2014; 32(2): 539-52.

[http://dx.doi.org/10.1016/j.ncl.2013.11.008] [PMID: 24703544]

[36] Klasser G. Management of persistent idiopathic facial pain. J Can Dent Assoc 2013; 79: d71.

[PMID: 23763745]

[37] Klasser GD, Epstein JB. Oral burning and burning mouth syndrome. J 
Am Dent Assoc 2012; 143(12): 1317-9

[http://dx.doi.org/10.14219/jada.archive.2012.0093]

[PMID:

23204086]

[38] Coculescu EC, Tovaru S, Coculescu BI. Epidemiological and etiological aspects of burning mouth syndrome. J Med Life 2014; 7(3):
305-9.

[PMID: 25408745]

[39] Feteih RM. Signs and symptoms of temporomandibular disorders and oral parafunctions in urban Saudi Arabian adolescents: A research report. Head Face Med 2006; 2: 25.

[http://dx.doi.org/10.1186/1746-160X-2-25] [PMID: 16914032]

\section{C) 2020 Emad Mohammed Hadlaq}

This is an open access article distributed under the terms of the Creative Commons Attribution 4.0 International Public License (CC-BY 4.0), a copy of which is available at: https://creativecommons.org/licenses/by/4.0/legalcode. This license permits unrestricted use, distribution, and reproduction in any medium, provided the original author and source are credited. 